\title{
(6) OPEN ACCESS \\ Gonadotropin ratio affects the in vitro growth of rhesus ovarian preantral follicles
}

\author{
Yoon Young Kim, ${ }^{1}$ Jun-Won Yun, ${ }^{2}$ Jong Min Kim, ${ }^{3}$ Chung Gyu Park, ${ }^{3}$ \\ Zev Rosenwaks, ${ }^{4}$ Hung Ching Liu, ${ }^{4}$ Byeong-Cheol Kang, ${ }^{2}$ Seung-Yup Ku ${ }^{1}$
}

${ }^{1}$ Department of Obstetrics and Gynecology, Seoul National University Hospital, Seoul, Republic of Korea ${ }^{2}$ Department of Experimental Animal Research, Biomedical Research Institute, Seoul National University Hospital, Seoul, Republic of Korea ${ }^{3}$ Xenotransplantation Research Center, Seoul National University College of Medicine, Seoul, Republic of Korea

${ }^{4}$ Center for Reproductive Medicine and Infertility, Weill Cornell Medical College, New York, New York, USA

\section{Correspondence to} Professor Seung-Yup Ku, Department of Obstetrics \& Gynecology, Byeong Cheol Kang, DVM, PhD. Primate Research Center, Seoul National University College of Medicine, 28 Yonkeundong Chongno-gu, Seoul 110-744, Republic of Korea; jyhsyk@snu.ac.kr

YYK and JWY contributed equally.

Accepted 2 February 2016

Copyright @ 2016 American Federation for Medical Research

\section{CrossMark}

\author{
To cite: Kim YY, Yun J- \\ W, Kim JM, et al. J \\ Investig Med \\ 2016;64:888-893.
}

\section{ABSTRACT}

In vitro follicle growth (IVFG) strategy is critical in the fertility preservation of cancer survivors; however, its optimal protocol needs to be developed using primate models since the availability of human samples is limited. Only a few previous studies have reported the successful IVFG of rhesus monkey ovaries using low-dose follicle-stimulating hormone (FSH) $(0.3$ or $3 \mathrm{ng} / \mathrm{mL}$ ) and long-term culture (up to 5 weeks) and it is still uncertain in regard to the optimal culture duration and effective dose of treated gonadotropins applicable to the IVFG of rhesus preantral follicles. Recently, we have reported that the FSH to luteinizing hormone $(\mathrm{LH})$ ratio affects the in vitro growth of murine ovarian follicles. We aimed to investigate whether gonadotropin ratios affect the efficiency of rhesus follicular growth in vitro. Ovaries were collected from six necropsied rhesus macaques (4-9 years) and preantral follicles were retrieved and cultured for 14 days using $200 \mathrm{mIU} / \mathrm{mL}$ FSH. The characteristics of follicular growth were compared between the FSH: $L H=1: 1(n=24)$ and FSH:LH=2:1 ( $n=24)$ groups. High concentration gonadotropin treatment shortened the duration required for in vitro maturation of rhesus preantral follicles. The FSH:LH=2:1 group showed a faster follicular growth and enabled the acquisition of mature oocytes, although the expression of growth differentiation factor (GDF)-9 and anti-Müllerian hormone (AMH) did not differ significantly between the two groups. Taken together, high dose gonadotropin treatment can shorten the duration of IVFG and the gonadotropin ratio is important in the IVFG of rhesus monkey ovaries.

In vitro ovarian follicular growth (IVFG) has been used as a study model of early folliculogenesis, ${ }^{1}$ and recently tested as a fertility preservation technique since it can avoid the risk of reimplantation of malignant cells. ${ }^{2}{ }^{3}$ Various animals have been adopted for this investigational use: mice, ${ }^{4}$ rats, ${ }^{5}$ bovines, ${ }^{6}$ monkies, ${ }^{7}$ and so on. Among them, murine models are widely used; however, the critical difference between rodents and primates, such as absence of menstruation and super multi-fetal gestation in rodents, may hinder the extrapolation of retrieved murine data to the interpretation toward any possible clinical implication. To overcome this hurdle, the use of and data acquisition from non-human primate models can be a reasonable option.

\section{Significance of this study}

\section{What is already known about this subject?}

- In vitro follicle growth (IVFG) strategy is critical in the fertility preservation of cancer survivors; however, its optimal protocol needs to be developed using primate models since the availability of human ovary samples is limited.

- Although previous studies have reported the successful IVFG of rhesus monkey ovaries using low-dose follicle-stimulating hormone (FSH) $(0.3$ or $3 \mathrm{ng} / \mathrm{mL})$ and long-term culture (up to 5 weeks), it is still uncertain in regard to the optimal culture duration and effective dose of treated gonadotropins applicable to the IVFG of rhesus preantral follicles.

- Recently, we have reported that the FSH to luteinizing hormone (LH) ratio affects the in vitro growth of murine ovarian follicles, but whether this finding in rodents can apply to primate models is not known as yet.

\section{What are the new findings?}

- High concentration gonadotropin treatment shortened the duration required for the in vitro maturation of rhesus preantral follicles.

- The FSH:LH=2:1 group showed a faster follicular growth and enabled the acquisition of mature oocytes.

\section{How might these results change the focus of research or clinical practice?}

- The use of effective doses can reduce the duration of IVFG, which in turn improves the efficacy scientifically and practically if applied to clinical laboratories.

To date, the limited number of reports suggested different doses of treated gonadotropins and culture durations applied to the IVFG of rhesus monkey ovaries. Regarding the in vitro culture of secondary follicles (diameter of 130 $366 \mu \mathrm{m})$, a few previous reports on the rhesus monkey ovary IVFG used an extended culture duration, that is, 4-5 weeks and a low dose of 
follicle-stimulating hormone (FSH) $(0.3$ or $3 \mathrm{ng} / \mathrm{mL}) .{ }^{8}{ }^{9} \mathrm{In}$ case of small antral follicle (diameter $>500-2000 \mu \mathrm{m}$ ) culture in vitro, some groups used $75-220 \mathrm{mIU} / \mathrm{mL} \mathrm{FSH}$ with or without $75 \mathrm{mIU} / \mathrm{mL}$ luteinizing hormone $(\mathrm{LH})$ for 36-48 h. ${ }^{10} 11$

The optimisation of preantral follicle IVGF conditions is important in the context of fertility preservation. However, it is still uncertain in regard to the optimal dose and effective combination of gonadotropins which can be used for IVFG of rhesus preantral follicles. Recently, we have reported the efficacious ratio of two gonadotropins (FSH:LH) when murine follicles were grown in vitro. ${ }^{12}$ In this investigation, we attempted to elucidate (1) whether the IVFG with high dose gonadotropins can shorten the culture duration, and (2) whether two different FSH:LH ratios (1:1 vs 2:1) produce different IVFG efficiency, when the ovaries were collected from necropsied rhesus monkeys.

\section{MATERIALS AND METHODS Animals}

Rhesus macaque monkeys that were imported from China and of conventional health status were used in this study. ${ }^{13}$ During the studies, the animals were maintained in cages measuring $105 \times 75 \times 80 \mathrm{~cm}$ (height $\times$ width $\times$ depth) with a squeeze-back mechanism in a temperature-controlled and light-controlled room $\left(24 \pm 2^{\circ} \mathrm{C}, 40-60 \%\right.$ humidity, and $12 \mathrm{~h}$ light/dark cycle). They were allowed to have access to a commercial pelleted diet supplemented with vitamin D (2050 Teklad Global 20\% Protein Primate Diet, Harlan Teklad, Madison, Wisconsin, USA) and fresh fruit with tap water ad libitum, and remained under intensive veterinary supervision to monitor good health and body condition including attitude, appetite or behavior. Animals were sacrificed by intravenous injection of $10 \mathrm{~mL}$ of saturated $\mathrm{KCl}$ after anesthesia with intravenous ketamine $(10 \mathrm{mg} / \mathrm{kg})$, medetomidine $(0.04 \mathrm{mg} / \mathrm{kg})$ and vecuronium $(0.2 \mathrm{mg} / \mathrm{kg})$. All of the animal studies were performed after receiving approval of the Institutional Animal Care and Use Committee of the Biomedical Research Institute at the Seoul National University Hospital (SNUH-IACUC No. 15-0032).

\section{Collection of ovaries}

Ovaries were collected from rhesus monkeys $(n=6)$ during necropsy procedures (figure 1). The abdomen was opened via surgical laparotomy. The uterus was identified and followed to fallopian tubes and ovaries bilaterally. From the excised tubo-ovarian complexes, the ovaries were transported to preparation media, minimum essential medium (MEM- $\alpha$, Invitrogen, Grand Island, New York, USA) supplemented with $10 \%$ of fetal bovine serum (FBS) (Invitrogen) and penicillin/streptomycin (Invitrogen).

\section{Follicle isolation and culture}

Preantral stage follicles were used in the present study. A modification from previous reports ${ }^{12} 1415$ is that ovaries were cut into pieces with a surgical blade and follicles were dissected under a stereomicroscope using 30 gauge needles in prewarmed preparation media. Isolated follicles were individually cultured in medium MEM- $\alpha$, supplemented with $10 \% \mathrm{FBS}, 5 \mu \mathrm{g} / \mathrm{mL}$ insulin, $5 \mu \mathrm{g} / \mathrm{mL}$ transferrin, $5 \mathrm{ng} /$ $\mathrm{mL}$ sodium selenite (Invitrogen), $200 \mathrm{mIU} / \mathrm{mL}$ of recombinant human (rh) FSH (rhFSH, Gonal-F, Merck-Serono,

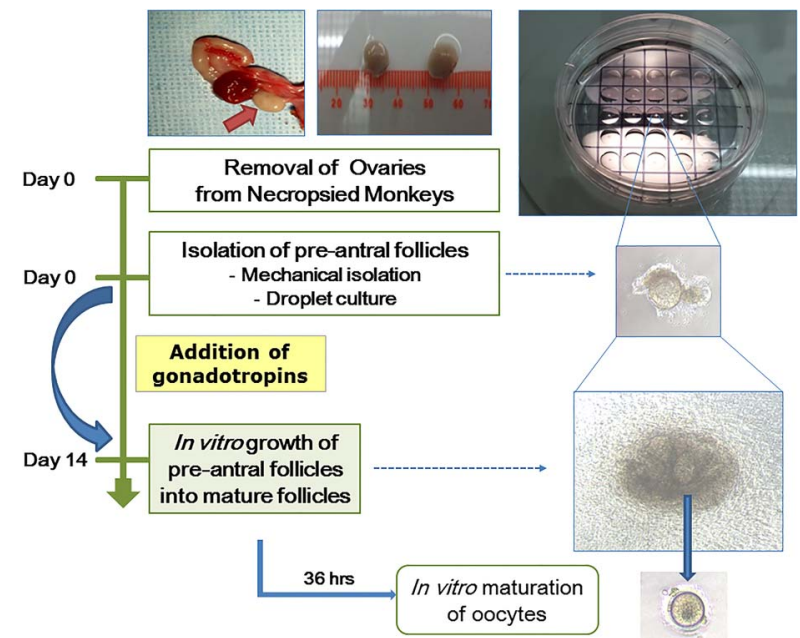

Figure 1 Schematic flow of experiments. The process of in vitro follicle growth is represented. Surgically collected rhesus monkey ovaries were used to isolate follicles which were then cultured in the individual droplets.

Germany), and 100 or $200 \mathrm{mIU} / \mathrm{mL}$ of rh luteinising hormone (rhLH, Luveris, Merck-Serono). Each follicle was seeded in a single media droplet $(300 \mu \mathrm{L})$ and then covered with mineral oil. Up to 25 follicles were seeded in a $60 \mathrm{~mm}$ embryo-grade culture dish (Nunc, Denmark). Half volume of the media was changed every other day. The attachment and growth of seeded follicles was observed using a phase contrast microscope.

\section{Measurement of growth and oocyte maturation}

The diameter of growing follicles was measured at day 2, day 9 and day 14 using the i-solution program (i-solution, Daejeon, Korea) and the mean diameter was calculated. At day 14, cumulus-oocyte complexes (COCs) were retrieved from grown follicles. Briefly, oocytes were mechanically isolated using 30 gauge needle and COCs were incubated with hyaluronidase (Sigma, St. Louis, Missouri, USA) for $5 \mathrm{~min}$ and washed. Oocytes were incubated in maturation media composed of MEM- $\alpha$, supplemented with $20 \%$ FBS, $5 \mu \mathrm{g} / \mathrm{mL}$ insulin, $5 \mu \mathrm{g} / \mathrm{mL}$ transferrin, $5 \mathrm{ng} / \mathrm{mL}$ sodium selenite (Invitrogen), 6-8 IU rhCG (Ovidrel, Merck-Serono), and $10 \mathrm{ng} / \mathrm{mL}$ rhEGF (Invitrogen). Isolated oocytes were assessed by a phase contrast microscope which analyzed their nuclear maturation stage as germinal vesicle metaphase I and metaphase II.

\section{Quantitative reverse transcription-PCR}

For PCR reaction, five follicles from each group were pooled and three sets were analyzed for the evaluation of

Table 1 Primer sequences for qRT-PCR

\begin{tabular}{lll}
\hline Gene & Forward $\left(\mathbf{5}^{\prime} \rightarrow \mathbf{3}^{\prime}\right)$ & Reverse $\left(\mathbf{3}^{\prime} \rightarrow \mathbf{5}^{\prime}\right)$ \\
\hline GAPDH & GAAGGTCGGTGTGAACGAAT & TTTGATGTTAGCGGGGTCTC \\
GDF9 & AACCCAGCAGAAGTCACCTC & AGGGGCTGAAGGAGGGAGG \\
AMH & GGGGAGACTGGAGAACAGC & AGAGCTCGGGGTCCCATA \\
\hline
\end{tabular}

AMH, anti-Müllerian hormone; GAPDH, glyceraldehyde-3-Phosphate Dehydrogenase; GDF, growth differentiation factor; qRT-PCR, quantitative reverse transcription-PCR. 
Table 2 Characteristics of necropsied monkeys used for ovary collection

\begin{tabular}{|c|c|c|c|c|c|}
\hline No & Species & Age & $\begin{array}{l}\text { Body } \\
\text { weight } \\
\text { (kg) }\end{array}$ & $\begin{array}{l}\text { Blood } \\
\text { type }\end{array}$ & Primary usage \\
\hline 1 & $\begin{array}{l}\text { Rhesus } \\
\text { macaque }\end{array}$ & $\begin{array}{l}5 \text { years } \\
3 \text { months }\end{array}$ & 5.3 & $A$ & $\begin{array}{l}\text { Pig pancreas islet } \\
\text { transplantation }\end{array}$ \\
\hline 2 & $\begin{array}{l}\text { Rhesus } \\
\text { macaque }\end{array}$ & $\begin{array}{l}4 \text { years } \\
10 \text { months }\end{array}$ & 5.1 & $A B$ & $\begin{array}{l}\text { Pig cornea } \\
\text { transplantation }\end{array}$ \\
\hline 3 & $\begin{array}{l}\text { Rhesus } \\
\text { macaque }\end{array}$ & $\begin{array}{l}8 \text { years } \\
11 \text { months }\end{array}$ & 5.6 & B & $\begin{array}{l}\text { Pig cornea } \\
\text { transplantation }\end{array}$ \\
\hline 4 & $\begin{array}{l}\text { Rhesus } \\
\text { macaque }\end{array}$ & 9 years & 6.1 & 0 & $\begin{array}{l}\text { Pig pancreas islet } \\
\text { transplantation }\end{array}$ \\
\hline 5 & $\begin{array}{l}\text { Rhesus } \\
\text { macaque }\end{array}$ & $\begin{array}{l}5 \text { years } \\
3 \text { months }\end{array}$ & 5.7 & B & $\begin{array}{l}\text { Pig cornea } \\
\text { transplantation }\end{array}$ \\
\hline 6 & $\begin{array}{l}\text { Rhesus } \\
\text { macaque }\end{array}$ & $\begin{array}{l}5 \text { years } \\
3 \text { months }\end{array}$ & 5.6 & B & $\begin{array}{l}\text { Pig cornea } \\
\text { transplantation }\end{array}$ \\
\hline
\end{tabular}

specific gene expression. Total RNAs were extracted from follicles using Trizol (Invitrogen). cDNAs were synthesized from $1 \mu \mathrm{g}$ of total RNAs and Accute premix (Bioneer, Daejeon, Korea). Each specific primer was added to the cDNA and the sequences are listed in table 1 . The amplification program included an initial step at $95^{\circ} \mathrm{C}$ for $10 \mathrm{~min}$, followed by 45 cycles of denaturation at $95^{\circ} \mathrm{C}$ for $15 \mathrm{~s}$ per cycle, an annealing step at $58^{\circ} \mathrm{C}$ for $20 \mathrm{~s}$. All the reactions were performed in triplicate and expression of $\mathrm{Ct}$ was calculated with glyceraldehyde-3-Phosphate Dehydrogenase (GAPDH) expression.

\section{Immunostaining}

To evaluate the localization of specific proteins, cells were washed with phosphate-buffered saline (PBS, Sigma) and fixed with 4\% paraformaldehyde (PFA, Sigma) for $15 \mathrm{~min}$ at room temperature (RT). To inhibit non-specific binding, 3\% bovine serum albumin (BSA, Sigma) solution was added to the cells and incubated for $1 \mathrm{~h}$ at RT. Primary antibody (1:100), rabbit anti-FSH receptor (SantaCruz Biotechnology, SantaCruz, California, USA) was applied for $1 \mathrm{~h}$ at RT. The cells were washed three times with PBS with Triton X100
(PBST, Sigma). The secondary antibody, Alexa Fluor 488-labeled donkey anti-rabbit IgG (Molecular Probes, Carlsbad, California, USA), was applied for $1 \mathrm{~h}$ at RT in the dark and washed three times with PBST. Cells were treated with the Prolong gold antifade reagent with 4',6-Diamidino2-Phenylindole (DAPI; Invitrogen) and analyzed using a fluorescence microscope (EVOS-FL, Life Technologies, Grand Island, New York, USA).

\section{Statistical analysis}

Each experiment was performed at least three times. Each variable was compared using analysis of variance and t test and $\mathrm{p}<0.05$ was considered as statistically significant.

\section{RESULTS}

\section{Basal characteristics of animals}

The age of animals was 4 years 10 months to 9 years, and body weight was $5.1-6.1 \mathrm{~kg}$. The distribution of blood type was one $\mathrm{A}, \mathrm{AB}, \mathrm{O}$ type each and $\mathrm{B}$ type in others. Two animals had been used for pig pancreas transplantation and four for pig cornea transplantation (table 2).

\section{Follicular growth characteristics}

The attachment of individually separated follicles was observed at day 1. Initial follicular diameter was in a range of approximately 220-380 $\mu \mathrm{m}$. They expanded with accumulation of follicular fluid. However, in contrast to murine IVFG, the COCs did not ovulate with EGF and hCG treatment at day 14. After a mechanical tear of grown follicles, the retrieval of an oocyte was possible (figure 2). The proportion of dark or coarse follicles was not different between the two groups. Metaphase II oocytes were retrieved from the FSH:LH=2:1 group (table 3).

\section{Comparison of growth rate between different gonadotropin ratios}

When the diameter of follicles was measured at day 2, day 9 and day 14, the FSH:LH=2:1 group showed a faster growth rate $(p=0.014)$ and a greater diameter of preovulatory follicles $(p=0.017)$ (figure $3 \mathrm{~A})$. The increase in diameter was also greater in the $\mathrm{FSH}: \mathrm{LH}=2: 1$ group $(p=0.039)$ (figure 3B).
Figure 2 In vitro growth of rhesus monkey ovarian follicles. Preantral follicles were cultured in vitro using media supplemented with $(A)$ follicle-stimulating hormone (FSH, $200 \mathrm{mlU} / \mathrm{mL}$ ) and luteinizing hormone (LH, $100 \mathrm{mlU} / \mathrm{mL}$ ) or (B) with FSH $200 \mathrm{mIU} / \mathrm{mL}$ and LH $200 \mathrm{mIU} / \mathrm{mL}$.
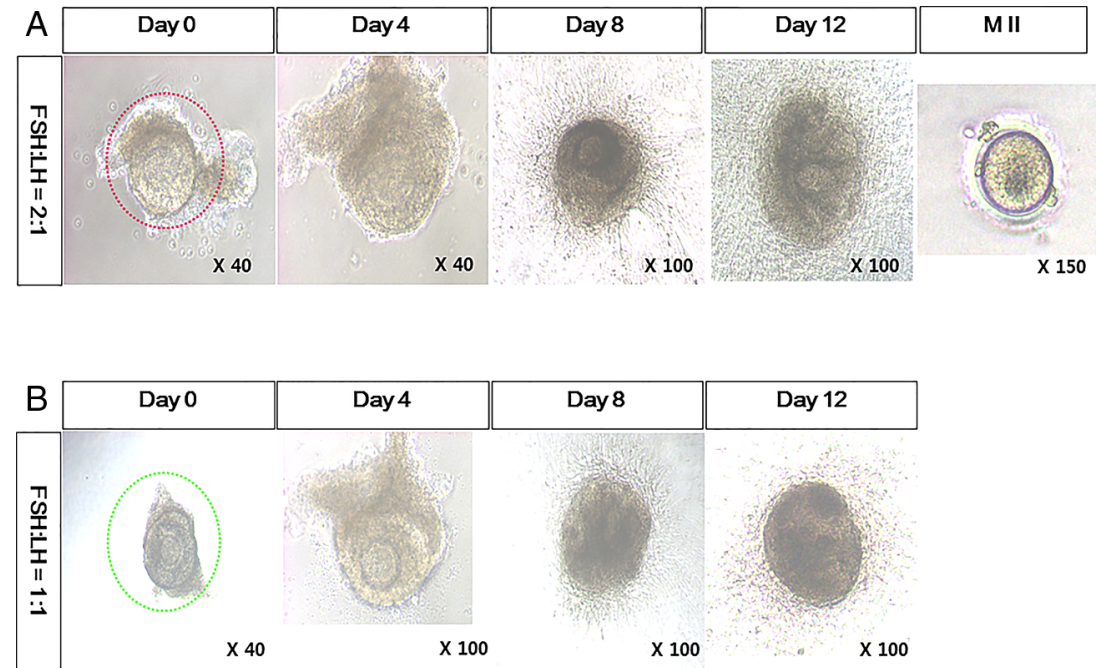
Table 3 Characteristics of follicles grown in vitro

\begin{tabular}{lll}
\hline & FSH:LH=2:1 & FSH:LH=1:1 \\
\hline $\begin{array}{ll}\text { Color } \\
\text { Dark }\end{array}$ & \\
Clear & $33 \%(8 / 24)$ & $42 \%(10 / 24)$ \\
Texture & $67 \%(16 / 24)$ & $58 \%(14 / 24)$ \\
Coarse & & \\
Silky & $25 \%(6 / 24)$ & $29 \%(7 / 24)$ \\
MIl/total & $75 \%(18 / 24)$ & $71 \%(17 / 24)$ \\
cf. Xu et al (2015) & $2 / 24$ & $0 / 24$ \\
MIl/total & & \\
\hline FSH, follicle-stimulating hormone; LH, luteinizing hormone. &
\end{tabular}

\section{Expression of GDF-9, AMH and FSH receptors on grown follicles}

The expression of GDF-9 and AMH on in vitro grown follicles in both groups at day 14 was comparable to that on antral follicles isolated at day 0 (figure 4A). The expression of FSH receptors was also comparable among the three groups (figure 4B). The FSH:LH=2:1 and $\mathrm{FSH}: \mathrm{LH}=1: 1$ groups did not show any difference in the expression of GDF-9, AMH and FSH receptors (table 4).

\section{DISCUSSION}

To the best of our knowledge, our study is the first to show that high dose gonadotropin treatment shortens the duration of IVFG using rhesus preantral follicles (220$380 \mu \mathrm{m})$ and that the gonadotropin ratio affects the IVFG efficiency in rhesus models as well as in murine models. As aforementioned, previous reports employed low dose, long-term culture for the IVFG of secondary follicles sized less than $366 \mu \mathrm{m}$ in diameter, ${ }^{8}{ }^{9}$ or high dose, short-term culture for the IVFG of small antral follicles sized larger than $500 \mu \mathrm{m}$ in diameter. ${ }^{1011}$

To date, a very limited number of groups reported rhesus monkey IVFG data and the number of animals is not large enough compared to murine models, due to the far stricter regulations ${ }^{16}$ and higher maintenance expense. Recently, two reports used only three or four rhesus monkeys for the IVFG without other interventions, which is comparable to our study setting. Those studies were designed to assess the

effects of various diets or the expression of markers on the in vitro grown rhesus follicles by treating with low-dose FSH for up to 5 weeks. ${ }^{8}{ }^{9}$ Despite this limitation, nonhuman primate data can provide an insight on the difference in the ovarian physiology from those of rodents, for example, EGF and hCG treatment used for induction of in vitro ovulation in murine models did not induce spontaneous release of COCs from in vitro grown rhesus follicles, which necessitates further investigations searching for optimized in vitro COC release protocols in rhesus models. To date, rhesus COC maturation data have been collected from the mechanically retrieved ones.

In clinical practice, either FSH only or an FSH and $\mathrm{LH}$ combination has been used for the controlled ovarian stimulation in in vitro fertilization (IVF) cycles. $^{17}$ Superiority of one over the other is still controversial because the individualization of stimulation protocols is necessary according to the basal hormone profiles of patients. Gonadotropin treatment is also essential in the IVFG of animal models. In many studies, only FSH was used, ${ }^{8-9} 11$ and in others a combination of FSH and $\mathrm{LH}$ was used. ${ }^{10}$ Our data showed that the FSH:LH of the 2:1 group was superior to that of the 1:1 group (figure 3). This is in line with our previous report on the optimal gonadotropin ratio during the IVFG in mice. ${ }^{12}$

A higher efficiency shown in the FSH:LH of the 2:1 group may have a clinical implication when polycystic ovarian syndrome (PCOS) is considered in terms of the FSH:LH ratio. PCOS is a common disorder associated with abnormal ovulation, affecting up to $10 \%$ of reproductive age women. For IVF patients with PCOS, it is common to observe a high cycle cancellation rate and relatively poor fertilization. A recent study showed that PCOS women had an $\mathrm{LH} / \mathrm{FSH}$ ratio of $1.5-1.7,{ }^{18}$ which is reversed compared to that of normal fertile women. In this context, the use of higher FSH and lower LH, for example, FSH:LH of 2:1, may probably show a better influence on the follicular growth.

The age of used animals is critical to the functional ovarian reserve. Most of the previous reports used rodents at the adolescent or pre-reproductive period, for instance 12-14-day-old mice, for IVFG of preantral ovarian follicles. ${ }^{12} 1415$ In previous studies using rhesus monkeys, they retrieved ovaries from the animals of 7-12 years for small

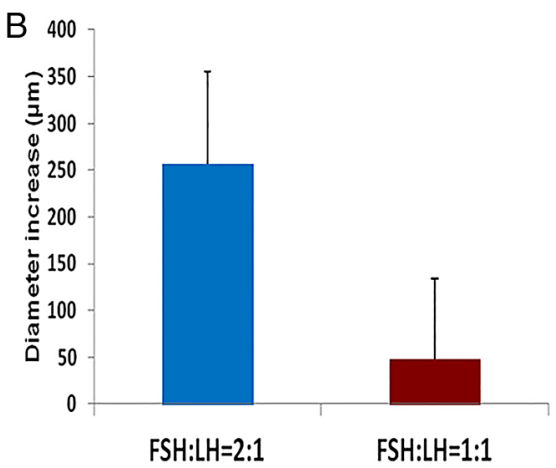

Figure 3 In vitro growth rate according to the gonadotropin ratio. Diameter of each in vitro grown follicle was measured by microscopic observation. The growth rate $(A)$ and the expansion rate (diameter at day 14-diameter at day 2) (B) were calculated. Error bars represent SDs.

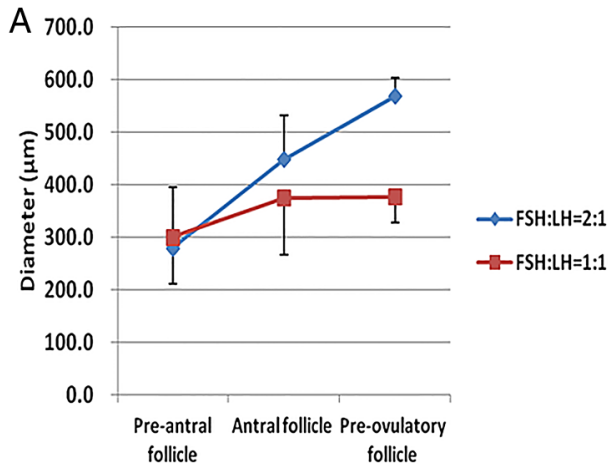

Kim YY, et al. J Investig Med 2016;64:888-893. doi:10.1136/jim-2015-000001 

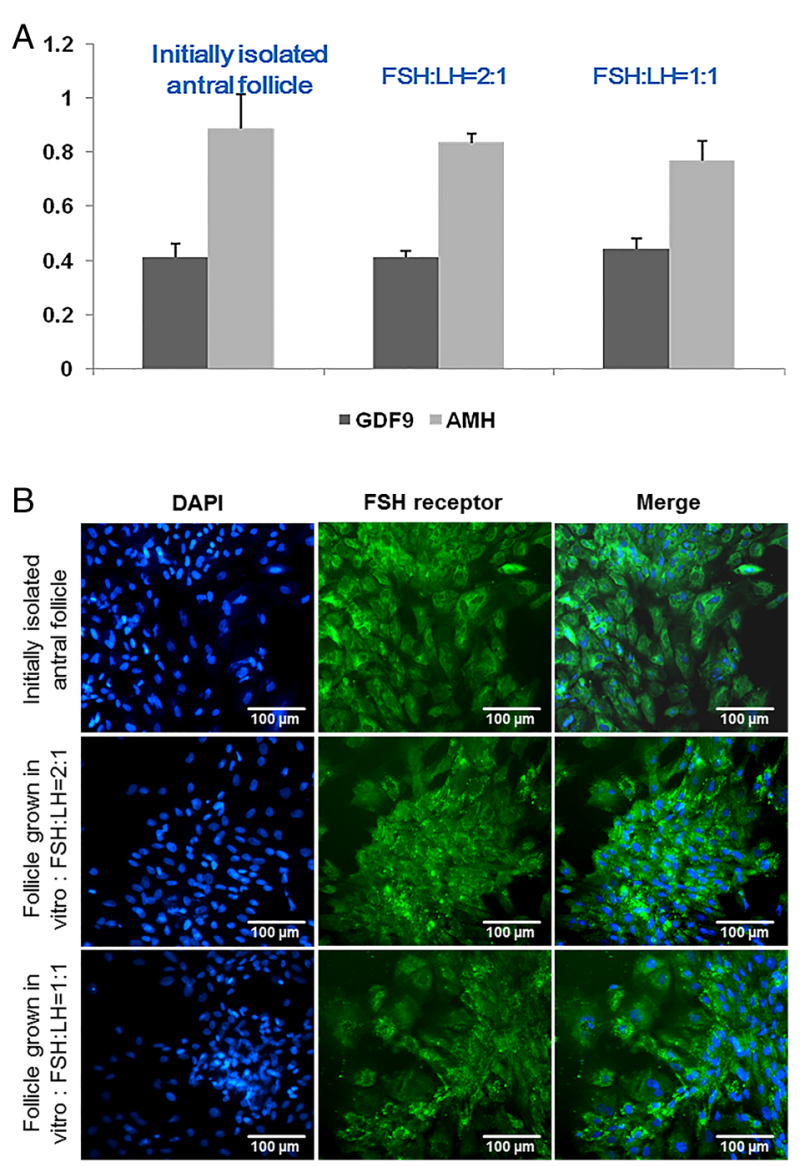

Figure 4 Gene expression on in vitro grown rhesus monkey ovarian follicles versus initially isolated antral follicles. Expression of GDF-9 and AMH (A), and FSHR (B) on initially isolated antral follicles and in vitro grown follicles. Error bars represent SDs. FSH, follicle-stimulating hormone. AMH, anti-Müllerian hormone; DAPI, 4',6-Diamidino-2-Phenylindole; FSHR, follicle stimulating hormone receptor; GDF, growth differentiation factor.

antral follicle culture ${ }^{1011}$ and from those of 4-17 years for secondary follicle culture $;^{8}{ }^{9}$ both ages correspond to mid to late reproductive period since their adolescence begins at around 2 years. Our animals were younger than those in previous reports, that is, 4-5 years and two 8-9 years. However, it is uncertain whether this age difference influenced the IVFG outcomes.
The ovarian physiology of used animals may have been influenced by the administration of immune suppressant medications ${ }^{19}$ because they had been used for the purpose of porcine pancreatic islet or cornea xenotransplantation. However, this possibility is considered to be minimal or absent since the use of those drugs was stopped at least 1 month before necropsy, although any previous irreversible functional damage may have remained.

Taken together, although the overall efficiency of mature oocyte acquisition still needs to be improved, it is feasible to use the ovaries collected from the necropsied rhesus monkeys which had been treated with immune suppressant medications. The FSH:LH ratio of $2: 1$ is more favorable compared to the $1: 1$ ratio in terms of IVFG rate and mature oocyte retrieval. Further larger scale studies are necessary that use ovaries of cynomolgus and marmoset monkeys to evaluate whether this tendency is applicable to other strains.

Acknowledgements The authors would like to express sincere thanks for the technical assistance of Jae Hoon Ahn, Jae Bum Ahn, Kyung Mon Roh, and Sang Young Park.

Contributors YYK and J-WY were involved in the in vitro experiments; $\mathrm{HCL}$, JMK and CGP were involved in the primate care; ZR was involved in the data management B-CK and S-YK were involved in the study design.

Funding This research was supported by grants (HI14C2289 and HI14C2259) from the Ministry of Health and Welfare, Republic of Korea.

Competing interests None declared.

Ethical approval All of the animal studies were performed after receiving approval of the Institutional Animal Care and Use Committee of the Biomedical Research Institute at the Seoul National University Hospital (SNUHIACUC No. 15-0032).

Provenance and peer review Not commissioned; externally peer reviewed. Open Access This is an Open Access article distributed in accordance with the Creative Commons Attribution Non Commercial (CC BY-NC 4.0) license, which permits others to distribute, remix, adapt, build upon this work noncommercially, and license their derivative works on different terms, provided the original work is properly cited and the use is non-commercial. See: http:// creativecommons.org/licenses/by-nc/4.0/

\section{REFERENCES}

1 Ganji R, Nabiuni M, Faraji R. Development of mouse preantral follicle after in vitro culture in a medium containing melatonin. Cell J 2015;16:546-53.

2 Smitz J, Dolmans MM, Donnez J, et al. Current achievements and future research directions in ovarian tissue culture, in vitro follicle development and transplantation: implications for fertility preservation. Hum Reprod Update 2010;16:395-414.

3 Shea LD, Woodruff TK, Shikanov A. Bioengineering the ovarian follicle microenvironment. Annu Rev Biomed Eng 2014;16:29-52.

Table 4 Previous studies on rhesus ovarian follicle culture in vitro

\begin{tabular}{|c|c|c|c|c|}
\hline References & $\begin{array}{l}\text { Monkey } \\
\text { Species }\end{array}$ & Age (years) & $\mathrm{n}$ & $\begin{array}{l}\text { Gonadotropin concentration (duration) } \\
\text { Initial follicle isolation stage (diameter) }\end{array}$ \\
\hline Merz et $a l^{8}$ & Rhesus macaques & $7-12$ & 4 & $\begin{array}{l}\text { FSH } 3 \mathrm{ng} / \mathrm{mL} \text { ( } 30 \text { days) } \\
\text { Secondary follicles (152-366 } \mu \mathrm{m})\end{array}$ \\
\hline Xu et al $\left.\right|^{9}$ & Rhesus macaques & $7-7.3$ & 3 & $\begin{array}{l}\text { FSH } 3 \mathrm{ng} / \mathrm{mL} \text { ( } 3 \text { weeks), } 0.3 \mathrm{ng} / \mathrm{mL} \text { ( } 4-5 \text { weeks) } \\
\text { Secondary follicles }(130-220 \mu \mathrm{m})\end{array}$ \\
\hline Peluffo et al ${ }^{11}$ & Rhesus macaques & average 8.6 & 5 & $\begin{array}{l}\text { FSH } 220 \mathrm{mlU} / \mathrm{mL}(34 \mathrm{~h}) \\
\text { Small antral follicles (>500 } \mu \mathrm{m})\end{array}$ \\
\hline Peluffo et $a l^{10}$ & Rhesus macaques & $4-17$ & 14 & $\begin{array}{l}\text { FSH } 75 \mathrm{mlU} / \mathrm{mL}+\mathrm{LH} 75 \mathrm{mlU} / \mathrm{mL}(48 \mathrm{~h}) \\
\text { Small antral follicles }(0.5-2 \mathrm{~mm})\end{array}$ \\
\hline
\end{tabular}

FSH, follicle-stimulating hormone; LH, luteinizing hormone. 
4 Picton $\mathrm{HM}$, Harris SE, Muruvi W, et al. The in vitro growth and maturation of follicles. Reproduction 2008;136:703-15.

5 Demeestere I, Centner J, Gervy C, et al. Impact of various endocrine and paracrine factors on in vitro culture of preantral follicles in rodents. Reproduction 2005:130:147-56.

6 Langbeen A, De Porte HF, Bartholomeus E, et al. Bovine in vitro reproduction models can contribute to the development of (female) fertility preservation strategies. Theriogenology 2015;84:477-89.

7 Xu J, Xu M, Bernuci MP, et al. Primate follicular development and oocyte maturation in vitro. Adv Exp Med Biol 2013;761:43-67.

8 Merz C, Saller S, Kunz L, et al. Expression of the beta-2 adrenergic receptor (ADRB-2) in human and monkey ovarian follicles: a marker of growing follicles? J Ovarian Res 2015;8:8.

$9 \mathrm{Xu}$ J, McGee WK, Bishop CV, et al. Exposure of female macaques to Western-style diet with or without chronic T in vivo alters secondary follicle function during encapsulated 3-dimensional culture. Endocrinology 2015;156:1133-42.

10 Peluffo MC, Ting AY, Zamah AM, et al. Amphiregulin promotes the maturation of oocytes isolated from the small antral follicles of the rhesus macaque. Hum Reprod 2012;27:2430-7.

11 Peluffo MC, Hennebold JD, Stouffer RL, et al. Oocyte maturation and in vitro hormone production in small antral follicles (SAFs) isolated from rhesus monkeys. J Assist Reprod Genet 2013;30: 353-9.
12 Park KE, Ku SY, Jung KC, et al. Effects of urinary and recombinant gonadotropins on in vitro maturation outcomes of mouse preantral follicles. Reprod Sci 2013;20:909-16.

13 Shin JS, Kim JM, Kim JS, et al. Long-term control of diabetes in immunosuppressed nonhuman primates (NHP) by the transplantation of adult porcine islets. Am J Transplant. 2015;15:2837-50.

$14 \mathrm{Kim}$ YJ, Ku SY, Rosenwaks Z, et al. MicroRNA expression profiles are altered by gonadotropins and vitamin C status during in vitro follicular growth. Reprod Sci 2010;17:1081-9.

15 Kim YJ, Ku SY, Kim YY, et al. MicroRNAs transfected into granulosa cells may regulate oocyte meiotic competence during in vitro maturation of mouse follicles. Hum Reprod 2013;28:3050-61.

16 Ministry of agriculture, food and rural affairs. Sanitary regulation for imported primates. http://law.go.kr/LSW/admRullnfoP.do?admRulSeq=2000000025512

17 Speroff L, Fritz MA. Clinical gynecologic endocrinology and infertility. 7th edn. Lippincott Williams \& Wilkins, 2011:1223-32.

18 Rashidi B, Abediasl J, Tehraninejad E, et al. Simvastatin effects on androgens, inflammatory mediators, and endogenous pituitary gonadotropins among patients with PCOS undergoing IVF: results from a prospective, randomized, placebo-controlled clinical trial. J Investig Med 2011;59:912-16.

19 Brunner HI, Silva CA, Reiff A, et al. Randomized, double-blind, dose-escalation trial of triptorelin for ovary protection in childhoodonset systemic lupus erythematosus. Arthritis Rheumatol 2015; 67:1377-85. 